\title{
ASSISTÊNCIA DE ENPERMAGEM AO PACIENTE TETÂNICO NA UNIDADE DE TERAPIA INTENSIVA
}

\author{
Ana Cristina Mancussi e Faro* \\ Zilda dos Santos Lima**
}

FARO, A.C.M. \& LIMA, Z dos S. Assisténcia de enfermagem ao paciente tetânico na unidade de terapia intensiva. Rev. Esc. Enf. USP, Săo Paulo 23(1);一, abr. 1989.

As autoras elaboraram um estudo geral sobre o tétano, no adulto, especificando o planejamento da assistência de enfermagem na Unidade de Terapia Inrensiva. tensiva.

UNITERMOS: Assistência de enfermagem. Tétano. Unidade de terapia in-

\section{I - INTRODUÇĀO}

Em se tratando de uma doença cuja distribuição é mundial e, principalmente, por ser causa importante de morte, além de ser mais comum a sua concorréncia em freas agricolas e subdesenvolvidas, onde o contato com excrementos $e$ frequiente $e$ a imunizaçäo é inadequada, (GUYTON, 1978), sentimos que há uma necessidade premente de orientaçäo ds pessoas mais expostas.

A orientação deve ser explícita no tocante transmissão e à profilaxia, e isso se faz mesmo depois que um indivfduo $t$ acometido pela doença e acaba sendo internado em uma Unidade de Terapia Intensiva (UTI). A orientação e perfeitamente cabfvel ao paciente, familia dele a a toda a equipe de enfermagem.

Com essa perspectiva, apresentamos o relato de um caso.

Por ser um estudo que salienta a assistência de enfermagem relativa ao paciente tetanioo na UTI, optamos por abordar uma breve evolução com história médica e duas avaliaçóes baseadas na evoluçảo de enfermagem durante nossa permanexcia na UTI.

Com base no quadro clínico e nas necessidades do paciente, elaboramos um

\footnotetext{
- Enfe. Aux. do Endino do Deppo de Enfermagem MGdico-Cirúrgica da Eucola de Enfermagem da USP, Disciplines Introduchio a Enfermayem o Fundamentoos de Enfermagem I.

* Bafe do Inetituto do Coragio do Hoep. dea Clínicas de Faculdade de Medicina de USP.
} 
roteiro para o exame fisico, o qual foi testado nos pacientes tetânicos internados naquela ocasiza isto E, de maio a junho de 1987.

Diariamente, além dos cuidados gerais que ministrávamos, faźamos a evoluçăo dos pacientes conforme o roteiro proposto (ANEXO I), anotando as alteraçōes havidas. Os impressos utilizados para a evoluçăo eram os da própria instituiçăo.

Antes de descrevermos como planejamos e ministramos a assisténcia ao paciente tetanico em UTI, achamos importante oferecer algumas noçōes relativas à doença, isto $\hat{\epsilon}$, a fundamentação teórica sobre o tétano.

\section{II - TETANO - ASPECTOS GERAIS}

1. Definiçāo e transmissão: é uma doença aguda, infecciosa e não contagiosa, muito grave, cujo agente etiológico é o Clostridium tetani. A transmissão ocorre através de alguma lesăo na pele, a qual 6 contaminada por esporos do Clostridium tetani (BENENSON, 1983; BIER, 1978; HARRISON, 1983).

É comprovado que a extensāo da lesāo não varia proporcionalmente à contaminaçăo, podendo ocorrer através de ferimentos insignificantes até lacerações extensas (queimaduras, fraturas expostas).

Já o tétano neonatal ocorre, em geral, atravês da infecção no umbigo nāo cicatrizado e "tratado" com substâncias orgânicas contaminadas, (HARRISON, 1983).

2. Suscetibilidade e resistência: a suscetibilidade é geral, havendo, segundo HARRISON (1983) de 300.000 a 500.000 casos de tetano a cada ano, estando a taxa de mortalidade em tomo de 45\%.

HARRISON (1983), descreve ainda que näo há predileçäo racial pelo bacilo; há uma proporçăo de 2,5 homens para uma mulher (2,5:1), porque o homem se encontra mais exposto a ferimento acidental.

Quanto a imunidade, é sabido que esta nāo se desenvolve com o acometimento da doença.

\section{Caracterizaçăo bacteriologica do Clostridium tetani:}

E um bastonete que mede aproximadamente 3 a 4 micra de comprimento por 0,5 micron de largura e cujas extremidades são arredondadas formando longos filamentos com esporos terminais, o que the da a aparencia de uma baqueta de tambor (BIER, 1978).

Além de Gram positivo e anaeróbico, cresce em placa ágarsangue com vácuo entre 3 a $8 \mathrm{~mm}$, segundo BIER (1978).

Comprovadamente, o bacilo nxo e dotado de poder invasivo; instala-se e permanece no foco, produzindo duas toxinas diferentes: a tetanolisina e a tetanospasmina. 
A primeira causa o efeito bematotóxico (hemólise) sem grande impartincia na patogenia e a segunda causa um efeito neurotóxioo (atua no Sistema Nervoso Central - SNC). A tetanospasmina e de natureza protéica e possui um peso molocular de aproximadamente 67.000 , sendo uma das toxinas bacterianas de maior potencia, somente superada pela toxina botulínica.

A produçăo de toxina tethnica em feridas, referida por HARRISON (1983), e como que favorecida pela necrose tissular, corpos estranhos, sais de cálcio e infoç̧óes associadas, que estabelecem baixos potenciais de oxirredução. Já o caráter epidemiológico do bacilo é citado por alguns atores (BENENSON, 1983; BIER, 1978; HARRISON, 1983), sendo saprofito, habitualmente natural das camadas superficiais do solo rico em componentes orgánicos, alem do intestino de certos animais, desevolvendo-se bem nos climas quentes $e$ úmidos.

4. Manifestaçōes clínicas: HARRISON (1983) e BRUNER \& SUDDARTH (1977) afirmam que a infecçāo causada pelo bacilo do tetano é localizada, entretanto a exotoxina $t$ transportada para o SNC. No que se refere ao transporte dessa toxina, BIER (1978) cita duas hipóteses principais: a condução da exotoxina ocorre atraves dos nervos, atuando no SNC e, por via hematogenica, atuando no SNC e no sistema nervoso periférico. A primeira hipótese tem maior aceitação, pois os canais linfáticos neurais desembocam no canal torácico e não no cefalorraquidiano.

Pasternak apud HARRISON (1983) refere que a exotoxina (tetanospasmina) se fixa no tecido nervoso, servindo-lhe de receptor, um glicolipidio, sendo que após isso năo é possível ocorrer a separação do tocido.

Com relaç5 a aspecto bioqúmico da toxina, alguns autores (BIER, $1978 \mathrm{e}$ HARRISON, 1983) acreditam em uma açāo anticolinérgica ao nível das sinapses dos neurónios motores da medula (neutralizaçảo do modiador responsável pela despolarização da membrana do neurônio pós-sináptico após sua excitação pelo neurónio pré-sińptico).

Ao referirem-se quanto 20 período de incubação, a maioria dos autores já citados, limitam em tomo de 14 dias, sendo que as queiras mais comuns sấ: dor e espasticidade da mandibula com dificuldade para abrir a boca (espasmo dos músculos masseterir nos, TRISMO), alem de febrícula, cefaléia e inquietação. Com o evoluir da doenca, outros músculos vāo ficando comprometidos, aparecendo o RISO SARDÓNICO, devido \&s contraçōes dos músculos faciais da mímica.

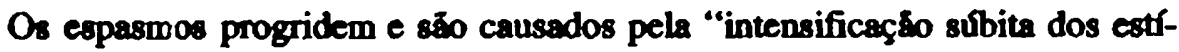
mulos aferentes que chegam periferia, aumentando a rigidez e causando simulta nea e excessiva dos músculos e seus antagonistas" (HARRISON, 1983).

Quanto a parte respiratória, esta é comprometida por leringopasmo ou pela própria contraça dos músculos respiratórios, havendo risco importante de hipoxia e consequente do SNC, irreversível $\approx$ ndo atendida em tempo hóbil. 
S£̊ ainda sinais e sintomas: taquicardia, hipertensão lábil, sudorese, disfagia, rigidez de nuca e de abdome. Vale ressaltar que, invariavelmente, na admissắ os pacientes estāo conscientes e orientados. Com o agravamento, entretanto, pela evoluçăo da doença, há necessidade de sedaçāo contínua.

Segundo HARRISON (1983), o prognóstico é bom, salvo complicaçōes como pneumonia ( 50 a $70 \%$ ), escaras de decúbito e infecçäo urinária.

5. Diagnóstico: o diagnóstico $\boldsymbol{C}$ inteiramente baseado nas manifestaçōes clfnicas, nāo dependendo portanto de confirmaçāo bacteriológica. Sabe-se que o líquido cafalorraquideano é absolutamente normal e que o Clostridium tetani somente em 30\% dos casos pode ser isolado no foco (HARRISON, 1983).

Não existem achados laboratoriais característicos da doença, logo nāo se usa fazer diagnóstico laboratorial de tétano.

6. Tratamento: geralmente o tratamento consiste de: debridamento radical do foco de contaminaçäo, antibioticoterapia, soro antitetânico, vacina antitetânica (1 - dose), miorelaxantes e sedativos (barbitúricos) e, no tétano grave, o curare.

Recorre-se a traqueostomia, ventilaçāo mecânica, catéter em via central, sonda naso-gástrica e sonda vesical de demora (Foley). A monitorização cardíaca se faz necessária.

7. Profilaxia: está firmada nos programas de imunização.

$O$ anticorpo atravessa a barreira placentária, o que faz diminuir a incidência de tétano neonatal.

\section{III - PLANEJAMENTO DA ASSISTÊNCIA DE ENFERMAGEM AO PACIENTE DA DOENÇA. RELATO DE UM CASO.}

Não foi possf́vel o desenvolvimento de todas as fases do "Processo de Enfermagem" de HORTA (1979), em vista de algumas dificuldades, tais como: o paciente encontrava-se constantemente sedado, não houve visita de familiares ou conhecido durante a nossa permanência na unidade, näo estivemos presentes na admissẩo do paciente, dados incompletos no prontuário.

Do prontuário do paciente, foram obtidas as seguintes informaçōes:

Em 10.05.89, internação - H.S.Z., 27 anos, ex-presidiário, procedente de Jundiá, refere que há um mês teve ferimento perfurante na região plantar do pé $\mathrm{E}$, com prego enferrujado, o qual uma semana apos estava com edema e rubor. Queixou-se, tambem, da dificuldade para abrir a boca e deglutir alimentos. Sedado, torporoso, trismo, afebril. Mantendo $\mathrm{PA}=12 / 8 \mathrm{cmHg}$ e $\mathrm{P}=80 \mathrm{bpm}$, há patéquias e localizadas no tronco e na região dorsal, rigidez abdominal e de nuca.

Foram prescritos $80 \mathrm{mg}$ de Diempax por dia.

A prescriçån médica compunha: 
1. Dieta para pesquisa de VMA (ácido vanil mandélico) e metanefrina por SNG, $200 \mathrm{ml}, 3 / 3 \mathrm{~h}$;

2. Claranfenicol $1 \mathrm{~g}$ EV $6 / 6$ hs;

3. Diempax 12 amp+SG $5 \% 500 \mathrm{ml} \mathrm{EV} 12 / 12 \mathrm{hs;}$

4. Diempax 1 amp. EV S/N;

5. Amplictil 1/2 amp. EV S/N;

6. Novalgina $2 \propto \mathrm{EV}$ se $\mathrm{T}=38^{\circ}$ ou para dor;

7. Aldrox $10 \mathrm{ml}$ por SNG $3 / 3 \mathrm{hs;}$

8. Hidróxido de $\mathrm{Mg} 10 \mathrm{ml}$ por $\mathrm{SNG}$;

9. Aminofilina 1 amp. EV + SG 5\% $250 \mathrm{ml}$ de $8 / 8 \mathrm{hs}$;

10. Água por gavagem $4 / 4$ hs. $200 \mathrm{ml}$;

11. KCL xarope $10 \mathrm{ml}$ SNG após as refeiçōes.

Com a evolução da doença, seu agravamento levou às seguintes condutas: traqueostomia ( $2^{\circ}$ dia de internação - DI) instalaçäo de um catéter em veia central (2․ DI), ventilaçăo mecânica (Bind em ventilação controlada), aumento das dosagens de Diempax en 15.05, de 12 ampolas para 18 ampolas; nesse mesmo dia passou a receber dieta obstipante, por sonda nasogástrica (SNG).

Com a melhora da diarreia, passou a receber dieta comum por SNG, em 18.05.

Procuramos retratar a seguir o quadro geral - 15 dias após a internação.

25.05.87: Exame físico e evolução de enfermagem: Consciente, orientado, atendendo ds ordens simples, porem muito sedado. Apresenta pupilas isoćricas e fotorreagentes, ptose palpebral bilateral, permanecendo corado, hidratado, acianotico, lábios ressecados.

Pediculose já tratada. Assistido pelo Bird com ventilação mandatória intermitente (IMV) (2:1), traqueostomizado, com secreçâo traqueal espessa e abundante, tambem ao redor da cknula, sialorreia intensa, trismo $+++14+$, riso sardonico, rigidez de nuca $+++14+$, rigidez abdominal $+++14+$, abdome plano $e$ indolor a palpacão, hipertonia de MMSS e MMII, com espasmos e sudorese importante.

Há discreto edema palpebral bilateral. Continua urinando espontâneamente, fazendo uso de uripen, portm em quantidade insatisfatória, concentrada, sem sedimentos. Ferimento perfurante na borda lateral do $p \in E$, ja debridado, e, em fase de cicatrizagta (foco). Recebendo oxigtnio $\left(\mathrm{O}_{2}\right)$ umidificado, 5 litros por minuto (5 1/min).

Está com sonda masogastrica fechada, em narina D; soro por "intracath" na veia subclávia E. Monitorizado, com especial atençảo à frequéncia cardíaca. 
A prescriçăo médica compunha:

1. Dieta normoproteica, hipercalórica por SNG $3 / 3$ hs;

2. Diempax 17 amp. $+5 \% 500 \mathrm{ml} \mathrm{EV} \mathrm{em} 12 \mathrm{hs;}$

3. Tagamet $1 \mathrm{cp}$. SNG 8/8 hs;

4. Claforan 2 g EV 12/12 hs;

5. Aminofilina 1 amp. + SG 5\% $100 \mathrm{ml} \mathrm{EV} \mathrm{em} 8$ hs;

6. KCL xarope $1 \mathrm{mod}$. VO 3 vezes a dia.

Quanto ao controle de sinais vitais, mantinham-se estáveis, entretanto, apresentava hipertensăo arterial lábil $(18 / 10 \mathrm{cmHg}, 14 / 9 \mathrm{cmHg}, 13 / 9 \mathrm{cmHg})$ e taquicardia momentånea. Estava em respiração espontânea (Bird em ventilação assistida + IMV), tendo iniciado o uso desta vál vula em 14.05, 4\% dia de internaçăo.

Durante higiene corporal, no leito, avaliamos boas condiçôes de pele (íntegra) e grande quantidade de esmegma.

Foi puncionada veia subclévia D para instalação de um novo catéter central, pois à esquerda apresentava discreta secreçăo purulenta e hiperemia na inserção.

A evoluçāo mostrou uma melhora significativa do paciente, levando-o a respirar espontaneamente a partir do $1^{\circ}$ dia de internaçāo, quando foi desligado do Bird. Elevou-se seu nfvel de consciência, sendo possível entendermos suas queixas e orientálo.

Quanto ao suporte medicamentoso, foram suspensas as dosagens de Diempax (17 amp.), mantendo essa droga somente como dose de ataque, e Amplictil 1/2 amp.

Verificamos ainda, um resultado de Ecocardiografia, o qual mostrou um prolapso de valva tricúspide. Outros resultados foram a sorologia para AIDS, ou seja, anti HIV negativo e gasometria arterial dentro dos parâmetros de normalidade.

Os espasmos, contraturas de membros inferiores, persistiam e, novamente, foram prescritos 9 ampolas de Diempax em soro Glicosado a $5 \%, 500 \mathrm{ml}$, durante

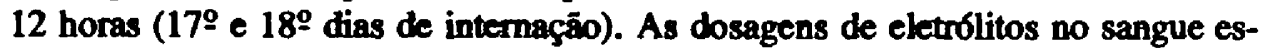
tavam normais, apesar do discreto edema palpebral bilateral e oligúria.

Precisamente no dia 28.05, notamos o nivel de consciência absolutamente normal, isto $t$, orientado auto e alopsiquicamente, sem sonolência, o que trouxe muita satisfaç̧̧o profissional a todos da equipe. Foi, entāo que iniciamos a orientaçăo, a qual serd descrita na assistênacia de enfermagem propriamente dita.

Mermo rescringido, o paciente retirou a SNG. Tentamos, entāo, avaliar sua deglutiç冖̆o oferecendo-lhe água por boca e nino obtivemos sucesso, sendo repassada a SNG. Devitb a disfagia e so quadro subito de diantia, a SNG permaneceu 
fechada para receber dieta obstipante.

Sem restrição ao leito, foi orientado quanto a SNG e deglutição.

Com base no exame físico proposto (ANEXO n), tem-se a seguinte evoluçāo, em 10 de junho:

Consciente, orientado, comunicando-se atraves de gestos, hidratado, acianotico, anictérico, descorado $++/ 4+$; afebril, normotenso, eupneico. Continua com pupilas isocóricas e fotorreagentes. Rigidez de nuca $+14+$, sem trismo e riso sardónico, traqueostomizado com secreção espessa e branca, em média quantidade, alimentando-se por boca. Presença de rigidez abdominal $3+/ 4+$, indolor à palpaçāo, ruidos hidro-aḱreos presentes (RHA+), hipertonia intensa dos MMII com dorso-flexâo dos pés, inversão acentuada do pé $D$, odema discreto na panturrilha E. Urinando espontaneamente c evacuaçăo normal. Foco totalmente cicatrizado.

Notamos que havia espasmos leves à palpacão abdominal. Informa sobre dor intensa nos MMII.

O fim do estudo de caso ocorreu no dia 2 de junho. Este paciente evoluiu conseguindo sentar com dificuldade, fazendo hidroterapia, com média quantidade de secreçāo traqueal espessa e apresentando as aspiraçōes, sudorese intensa na face e tronco. No dia 4 de junho recebeu transferéncia da UTI para a enfermaria.

\section{Plano Assistencial}

Retomando HORTA (1979), temos que o plano assistencial é a "determinaçāo global da assisténcia de enfermagem que o ser humano deve receber diante de diagnóstico estabelocido". Verificamos que o paciente tetánico, na UTI, tem um alto grau de dependência da enfermagem.

Por motivos didáticos, dividimos em tópicos o plano assistencial.

\subsection{Na recepşäo:}

É de suma importância lembrarmos que o tetânico näo possui, em função do quadro clínico, rebaixamento ou qualquer outra alteração do nível de consciência.

Ele, portanto, deve ser orientado com relaçăo a que acontoce ao seu redor e com ele próprio.

Este $t$ o momento mais adequado, salvo algumas intercorréncias, para realizarmos o Histórico de Enfermagem e o exame físico inicial. Tais dados fornecerão parámetros para individualizarmos nossas condutas, melhorando a assistência de enfermagem.

Vale salientar que o paciente tetánico é admitido diretamente na UTI, o que aumenta consideravelnente sus ansiedade e a de sua familia.

Consideramos, tambem, como assistencia de enfermagem o planejamento da unidade do paciente. Isto inclui desde a arnumação de cama, previsāo de material a ser utilizado (sondas de aspiracico, luvas, f́gua destilada, gaze, SNG, uripen, son- 
da Foley, papagaio, comadre, etc) aspirador portátil ou fixo a parede, monitor cardíaco, torpedo de ar comprimido.

Verificar, se está em ordem, a rede de oxigênio e ar comprimido canalizado.

Prever e prover situação de emergéncia - como insuficiência respiratória aguda e necessidade de traqueostomia ou iminência de parada cárdio-respiratória - instalado catéter e soro em veia central; o que significa ter o material diariamente revisado, conferido, à mão: caixas de pequena cirurgia, catéteres intravenosos (intracath), antissepticos e outros.

Concomitante a esses cuidados, a enfermeira deve reconhecer os sinais e sintomas do tétano, bem como toda a progressäo da doença.

Embora paradoxal, 80 recebermos o paciente, seja na UTI ou na unidade de internaçăo comum, é importante salientar que fica implícito, na orientaçāo, também o preparo para a alta. Há pois, por parte da enfermeira, a compreensão, a empatia em captar qualquer progresso alcançado pelo paciente, encorajando-o com frases como: "a continuar assim, o senhor terá alta em breve! Muito bem, tente abrir melhor os olhos, abrir um pouco mais a boca... Isso, estique as pernas!...".

Especificamente no tetânico, a prevençāo de deformidades (dorso-flexāo dos pés, flexão de punhos entre outras) e cuidados com a pele (escaras) são também fundamentais.

No caso estudado, nāo estávamos presentes à admissāo na UTI; assim prestamos cuidados diretos a partir do quarto dia de internação já com o paciente muito sedado.

\subsection{Na fase aguda da doença:}

Em geral, nesta fase (salvo tétano localizado) o paciente encontra-se muito sedado devido aos espasmos e contraturas, assim como para rebaixar o nível de consciência (... "o tetânico ê um espectador lúcido do seu próprio sofrimento" HARRISON (1983). Especificamos, novamente, que para tornar esse relato mais didático e verdadeiro, todos os cuidados foram por nós prestados durante a nossa permanência na UTI.

\section{CUIDADOS DE ENFERMAGEM COM RELAÇÃO AO NÍVEL DE CONSCIENCIA:}

Verificar se, mesmo sedado, o paciente atende aos chamados.

Informar sobre qualquer procedimento.

Localizar no tempo e no espaço (dia, més, hora e local).

Informar sobre visitas que tem recebido. 


\section{CUIDADOS DE ENFERMAGEM QUANTO AO POSICIONAMENTO:}

Manter o paciente em cama com grades (levantadas).

Fazer mudança de decúbito.

Colocar: apoios sob os joelhos (flexăo de 15:; anteparo nos pés; órteses improvisadas - com lençol, espuma, fronha ou outro material - impedindo deformidades das măos e punhos; apoio sob os calcâneos e cotovelos, regiäo sacra (uso de almofadas d'água), nas costas (em lateral). Observaçāo: $o$ colchão d' água causa grande instabilidade para esses pacientes.

\section{CUIDADOS DE ENFERMAGEM COM IMOBILIZAÇĀO DO PACIENTE:}

Evitar o uso da restriçāo em " 8 ".

Proteger as saliéncias ósseas.

Verificar, regularmente, pulso proximal, coloração e temperatura do membro restringido.

Observar presença de edemas.

E um detalhe importante nāo só pela restrição, mas também, porque os espasmos e contraturas podem levar a danos mais sérios.

\section{CUIDADOS DE ENFERMAGEM NA MANUTENÇĀO DA VENTILAÇÃO:}

Aspirar sempre que necessário, com técnica asséptica, cânula de traqueostomia, boca c narinas.

Manter cánula livre de secreçāo.

Trocar o cadarço da cânula diariamente.

Manter a pele do pescoço limpa e seca.

Manter "cuff" insuflado.

Controlar aparelhos, aspiradores, extensōes, rede de vácuo de oxigênio, e de ar comprimido, para sempre propiciar funcionamento adequado.

Manter nebulizaçāo contŕnua.

\section{CUIDADOS DE ENFERMAGEM COM INFUSŌES E DRENAGENS:}

Posicionar, confortavelmente, a sonda nasogástrica e a sonda vesical de demora. Observar lesóes causadas pelas sondas.

Trocar sonda Foley, conforme rotina preconizada na UTI.

Colher material (secreça brónquica, urina), conforme rotina preconizada. 
Fazer limpeza de meato uretral externo e narinas diariamente.

Trocar curativo de intracath diariamente (oclusivo).

Manter intracath permébel.

Controlar infusão de soro (dosagem e gotejamento).

Controlar a infusto da dieta (gotejamento ou por gavagem).

Controlar diurese (volume e aspecto).

Fazer balanço hídrico de 24 horas e por plantão.

\section{CUIDADOS DE ENFERMAGEM COM PELE E MUCOSAS:}

Usar emoliente sempre que necessário.

Fazer prevenção de escaras.

Trocar, diariamente, curativos das escaras.

Identificar o foco e inspecionar condiçōes.

Fazer curativo do foco, diariamente e quantas vezes forem necessárias, observando condições (secreção, necrose, hiperemia, odor, tecido de granulação).

Colocar, após limpeza ocular com água boricada, colírio neutro ou pomada com vitamina $\mathrm{A} \mathrm{e} \mathrm{D}$, se necessário cobrir com gaze úmida.

Observar coloração e integridade das mucosas.

\section{CUIDADOS DE ENFERMAGEM QUANTO À HIGIENE CORPORAL E ORAL:}

Dar banho no leito. Sempre que possível esse cuidado será aplicado por uma enfermeira e um funcionário da UTI.

Fazer higiene oral com água bicarbonatada.

Retirar crostas dos lábios com uso de emolientes.

Fazer higiene intima minuciosa, observando presença de secreção, esmegma, lesōes, irritaçōes.

Evitar excesso de sabão, durante o banho, pois resseca a pele.

Secar espaços interdigitais e dobras em geral.

Aparar as unhas.

\section{CUIDADOS DE ENFERMAGEM COM RELAÇĀO A FAMfLIA:}

Embora durante a realização deste estudo, nāo tenhamos entrado em contato com familiares, $t$ importante: 
- Oriontar quanto a quadro clínico e quanto a assiaténcia de enfermagem prestada.

- Orientar no sentido de profilaxia da doença, vendo-a como agentes multiplicadores das informaçöes.

\section{ORIENTAÇĀO E TREINAMENTO DA EQUIPE DE ENFERMAGEM:}

Orientar a evitar acidentes de trabalho.

Ensinar a manusear o paciente grave, com infusōes e drenagens, além de aparelhos.

Manter a unidade do paciente organizada, de modo que o acesso ao paciente seja fúcil, evitando a mecânica corporal incorreta.

Orientar quanto à doença e respectiva assistência de enfermagem.

\subsection{Na fase de recuperação:}

Em geral, é uma fase muito gratificante, pois após a fase onde o paciente era totalmente dependente da enfermagem, agora, comecamos a reedućtlo.

Vemos, então, os resultados da nossa assistência de enfermagem, e a importância do seu planejamento.

Temos, ainda, como objetivo, diminuir o grau de dependência do paciente com relação à enfermagem.

Saímos da fase do "FAZER" e passamos para a fase do "AJUDAR".

Verifica-se ainda nesta fase, possíveis seqüelas tais como fraturas de costelas e coluna, devido as espasmos e contraturas intensas.

Neste planejamento de rectucacåo do paciente, temos que estar cientes, ainda, para alguns sinais e sintomas do tétano residual para que nossas orientaçōes não causem mais ansiedade no paciente por este querer fazer tudo.

Vamos, entäo, "AUUDAR" o paciente a:

- mudar de docubibito;

- tossir e expelir secregäa;

- alimentar-se (com supervisāo);

- mastigar correta e vagarosamente os alimentos;

- deglutir cautelosamente;

- assumir postura e relaxamento muscular;

- fazer uso de papagaio e comadre;

- sentar-se no leito;

- sentar-se na cadeira; 
- tomar banho e aspersão;

- fazer hidroterapia (banheira);

- comunicar-se por gestos, se conseguir, por mímica facial e até escrever, se for alfabetizado.

- colaborar nas sessão de fisioterapia.

É válido dizer que, nesta fase, o paciente ainda se encontra na UTI, embora a assistência de enfermagem a ele prestada tenha características de unidade de cuidados semi-intensivos.

Com o aumento da não-dependência da enfermagem, a alta da UTI ocorre rapidamente, sendo encaminhado para a unidade de internação onde, também, será ajudado no treino de marcha.

A propósito dos cuidados de enfermagem citados anteriormente, elaboramos um ftem para os cuidados de enfermagem com medicamentos e, neste estudo, apresentaremos, especificamente, as medicaçōes utilizadas no Paciente H.S.Z.

Entretanto, como já citamos no ítem Tratamento, as medicaçöes utilizadas nos tetânicos são similares, salvo no caso de tétano grave, onde o paciente é curarizado (além de se fazer uso de barbitúricos).

Nåo especificamos aqui os cuidados com o paciente curarizado, pois o paciente escolhido nāo necessitou desse tratamento $\mathrm{e}$, também, porque a literatura é rica nesse aspecto.

\section{CUIDADOS DE ENFERMAGEM COM MEDICAMENTOS:}

Tais cuidados referem-se ao preparo e administração de drogas, com o conhecimento de efeitos desejáveis e colaterais.

1. antibioticos.

1.1. Grupo Cefalosporinas - Claforan.

Semi-sintético, amplo espectro, atingindo bactérias gram positivas e gram negativas. É indicado em infeç̧ão bacterianas agudas e crônicas. Possui ação bactericida.

\subsection{Largo espectro-Cloranfenicol.}

Possui açāo bacteriostática, atingindo bactérias gram positivas e gram negativas. É indicado nas afeç̧ōes agudas das vias respiratórias, assim como em algumas outras infecções.

Assistência de Enfermagen:

Executar as diluiçôes corretamente, por via adequada e no horário correto, observando o local de infusāo. 
Reconhecer os sinais e sintomas de hipersensibilidade.

Reconhecer os efeitos colaterais tais como diartéa, náuseas, vómitos, resisténcia dos microrganismos.

Controlar termperatura em intervalos menores (4/4hs).

\section{Vasodilatadores:}

2.1. Arterial e Bronquiodilatador - Aminofilina.

Assistência de Enfermagem:

Diluir corretamente, fazendo uso de buretas e microgotas.

Controlar o gotejamento e local de infusão.

Controlar antes da infusāo PA, P, FR e, também, durante e após a mesma.

Reconhecer sinais de hipersensibilidade.

3. Hipnóticos e Sedativos:

Os hipnóticos são soníferos e os sedativos sâo drogas que reduzem a excitação cortical, sem induzir o sono (diminuem as atividades motoras).

Atuam no SNC, causando depressāo nervosa e respiratória, levam à vasodilataçāo e hipotensāo (barbitúricos).

Sāo eles Thionembutal, Gandenal, Luminal, etc.

Outros să usados na insónia, sedaçāo diurna e em pacientes sensíveis aos barbitúricos. Estes outros s.్

Assistência de Enfermagem:

Controlar rigorosamente os sinais vitais.

Observar diluiçāo correta quanto dosagem e uso do diluente apropriado.

Controlar gotejamento e local de infusão.

Observar via de administraçāo e sinais de intoxicaçāo.

4. Antidicidos:

4.1. Protetor da mucosa gastroduodenal, indicado para o tratamento de gastrites e úlceras. Tem indicação na prevenção das mesmas.

Assistência de enfermagem:

Observar dosagem, via e horário para administração.

Reconhecer alguns possíveis efeitos colaterais.

5. Xaropes:

5.1. Cloreto de Potássio (KCL)

"O potássio tem funçăo de relevo na síntese de proténas, especialmente na 
incorporaçäo de aminoácidos às cadeias de polipeptídeos. É de se deduzir que a migraçăo do potássio venha a prejudicar seriamente a síntese de proteínas específicas, dentre as quais merecem destaque as imunoproteínas, de que tanto necessita o organismo frente a qualquer agressão" (BRANCO MACHADO, 1987).

Embora nāo seja classificado, aqui, como medicamento, aparece em certa fase da doença uma prescriçāo médica de dieta para pesquisa de VMA (ácido vanilmandélico) e metanefrina. Segundo orientaçäo verbal do Serviço de Nutrição e Dietética do IC-HC, é uma dieta pobre em ácido fenólico, para nâo mascarar a produção de ácido vanilmandélico e metanefrina, as quais estão aumentadas durante $o$ acometimento por tétano.

\section{CONSIDERAÇŌES FINAIS}

Este foi um estudo realizado na UTI da clínica de Molestias Infecciosas do HCFMUSP, durante nossa permanência nesta unidade.

Atuamos efetivamente durante a evoluçāo de uma doença grave, com alto índice de mortalidade e, verificamos que a atuação do "enfermeiro-intensivista" baseia-se em:

- conhecer tudo sobre a doença, com perspectiva de encontrar a normalidade;

- estar atualizado quanto à assistência de enfermagem.

- e é, sobretudo, incorporar uma filosofia de trabalho dinámica, atual e de uniāo entre a equipe multiprofissional.

- executar os cuidados de enfermagem previamente planejados, visando a qualidade e a individualizaçăo destes, para prevenir ou minimizar as sequelas.

- orientar a equipe de enfermagem c comunidade, no que tange a doença, sua transmissão e profilaxia.

Recomenda-se o uso do roteiro para o exame físico do paciente tetânico proposto por FARO \& LIMA (ANEXO I), desde a recepção até a alta da UTI.

FARO, A.C.M. \& LIMA, Z. dos S. Nursing care of the tetanic patient in ICU. Rev.Esc.Enf.USP, São Paulo, 23(1): - Apr. 1989.

The authors have made a general study on tetanus of the adult and specified the nursing care planning in the Intensive Care Unity.

UNTTERMS: Nursing care. Tetanus. Intensive care units 


\section{REFERENCIAS BIBLIOGRÁFICAS}

BENENSON, A.S. TEamo. In:

Controle das doenças transomiasfrels no homem. 13.ed. Wahington, Organizagio Panmericama de Sadde, 1983. p.322-6. (publicaglio cientffica, 442).

BIER, O. Bacteriblectne tmanologla. 19.ed. Slo Paulo, Melhoramentos, 1978. p.548-61.

BRANCO, P.D. M MACHADO, M.C.C. Ectado de choque e seu tratamento. In: CORBETT, C.E. Farmecodtalmilca. 5. ed. Rio de Janeiro, Gunabara Koogan, 1987, p.467.

BRUNNER, L.S. a SUDDARTH, D.S. Enfermagem na doenga tranemissivel. In:

ferengen midiodirindea. 3.0d. Rio de Janeiro, Internmericans, 1977. p.1140-42.

En-

GUYTON, C.A. Thiologda birlea. 2. ed. Rio de Janoino, Interamericana, 1978. p.

HARRISON, T.R. Medicina interaa. 10.ed. Rio de Janeiro, Guanabara Koogan, 1983. p.1130-34.

HORTA, W. de A. Processo de enfermagem. SEo Paulo, EPU, 1979. 99p.

Rocebido em 20108/87 
EXAME FÍSICO DO PACIENTE TETÂNICO NA UTI.

NOME:

RG:

LEITO:

01) Nível de consciência e grau de orientação:

( ) consciente

( ) inconsciente

( ) sedado

( ) orientado

( ) confuso

( ) atende às solicitações verbais

( ) não atende às solicitaçōes verbais

(. ) reage aos estímulos dolorosos

02) Pupilas:

( ) fotorreagentes

( ) isocóricas

( ) médio-fixas

( ) midriaticas

( ) não reagentes

( ) anisocóricas

( ) mióticas

03) Mucosas:

bucal e lábios: ( ) íntegra ( ) corada ( ) descorada

lesōes:

nasal: ( ) íntegra lesōes:

conjuntival: ( ) íntegra ( ) corada ( ) descorada

04) Edemas:

( ) local:

05) Secreçöes:

local:

características:

06) Contraturas e Espasmos:

TRISMO:

RIDIGEZ DE NUCA:

OPISTÓTONO:

RISO SARDÔNICO:

ABALOS: RIGIDEZ ABDOMINAL: ESPASMOS:

07) Foco:

local: condiçōes:

08) Condiçōes de pele: escaras:

09) Alimentação: ( ) VO （ ) SNG （ ) SNE 
10 Eliminaçōes: ( ) sonda Foley evacuaçāo:

vómitos:

sudorese:

11) Aparelhos, Equipamentos e Infusôes:

( ) traqueostomizado

( ) Bird ( ) assistida ( ) controlada ( ) IMV ( ) PEEP

( ) Monaghan

( ) Monitor cardfaco

( ) Venodissecçāo

local:

( ) Intracath

local:

( ) Gelco

local:

( ) Butterfly

local:

enfermeira - coren

data 